Article

\title{
Coupling Fine-Scale Root and Canopy Structure Using Ground-Based Remote Sensing
}

\author{
Brady S. Hardiman ${ }^{1,6, *}$, Christopher M. Gough ${ }^{2}$, John R. Butnor ${ }^{3}$, Gil Bohrer ${ }^{4}$, Matteo Detto ${ }^{5}$ \\ and Peter S. Curtis 6 \\ 1 Department of Forestry and Natural Resources \& Division of Environmental and Ecological Engineering, \\ Purdue University, West Lafayette, IN 47907, USA \\ 2 Department of Biology and Environmental Studies, Virginia Commonwealth University, Richmond, \\ VA 23284, USA; cmgough@vcu.edu \\ 3 USDA Forest Service, Southern Research Station, 81 Carrigan Drive, Burlington, VT 05405, USA; \\ jbutnor@fs.fed.us \\ 4 Department of Civil, Environmental and Geodetic Engineering, The Ohio State University, Columbus, \\ OH 43210, USA; bohrer.17@osu.edu \\ 5 Smithsonian Tropical Research Institute, Unit 9100, Box 0948, DPO AA 34002-9998, Miami, FL 34002, USA; \\ dettom@si.edu \\ 6 Department of Evolution, Ecology and Organismal Biology, The Ohio State University, Columbus, \\ OH 43210, USA; curtis.7@osu.edu \\ * Correspondence: bhardima@purdue.edu; Tel.: +1-765-494-3593 \\ Academic Editors: Nicolas Baghdadi, Richard Gloaguen and Prasad S. Thenkabail \\ Received: 20 October 2016; Accepted: 16 February 2017; Published: 21 February 2017
}

\begin{abstract}
Ecosystem physical structure, defined by the quantity and spatial distribution of biomass, influences a range of ecosystem functions. Remote sensing tools permit the non-destructive characterization of canopy and root features, potentially providing opportunities to link above- and belowground structure at fine spatial resolution in functionally meaningful ways. To test this possibility, we employed ground-based portable canopy LiDAR (PCL) and ground penetrating radar (GPR) along co-located transects in forested sites spanning multiple stages of ecosystem development and, consequently, of structural complexity. We examined canopy and root structural data for coherence (i.e., correlation in the frequency of spatial variation) at multiple spatial scales $\leq 10 \mathrm{~m}$ within each site using wavelet analysis. Forest sites varied substantially in vertical canopy and root structure, with leaf area index and root mass more becoming even vertically as forests aged. In all sites, above- and belowground structure, characterized as mean maximum canopy height and root mass, exhibited significant coherence at a scale of 3.5-4 m, and results suggest that the scale of coherence may increase with stand age. Our findings demonstrate that canopy and root structure are linked at characteristic spatial scales, which provides the basis to optimize scales of observation. Our study highlights the potential, and limitations, for fusing LiDAR and radar technologies to quantitatively couple above- and belowground ecosystem structure.
\end{abstract}

Keywords: canopy; root; biomass; spatial wavelet coherence; radar; LiDAR

Highlights

- Canopy and root biomass are examined across a forest chronosequence.

- Colocated ground-based LiDAR and ground-penetrating radar data were collected.

- Spatial wavelet analysis reveals coherence in canopy height and root biomass.

- All ages exhibited coherence between canopy and root structures at a scale of 3-4 m; oldest stands demonstrated coherence at $8 \mathrm{~m}$.

- We demonstrate methods to quantify fine-scale patterns of root-canopy structure. 


\section{Introduction}

Ecosystem structure predicts a wide range of ecological functions, from carbon, nutrient, and water cycling to animal biodiversity. Measures of ecosystem structure expressing the quantity and/or distribution of above- and belowground biomass serve as important proxies for ecosystem functions, and accordingly are commonly used to parameterize ecosystem models [1,2]. For example, leaf surface area is a global predictor of primary production [3]. Belowground, root biomass distribution correlates with nutrient uptake and retention, which can in turn affect aboveground growth and structure $[4,5]$. Ecosystem water cycling and land-atmosphere gas exchanges similarly require understanding of above- and belowground structure, with canopy interception of precipitation affecting the distribution and quantity of soil water content and, consequently, plant water availability and root growth [6]. While above- and belowground structural interactions are relevant to these and other ecosystem functions, quantitative linkages between them are poorly characterized, particularly at fine spatial scales, owing in large part to challenges in quantifying belowground structure and the often-arbitrary scales at which they are compared.

Traditional approaches linking above- and belowground ecosystem structure at scales of several meters or less are time consuming, may require destructive sampling, and are often descriptive rather than quantitative [7-11]. For example, common methods of belowground biomass estimation include soil coring followed by the manual separation of soil and roots prior to weighing, or equally laborious root imaging (i.e., minirhizotron) protocols [12]. Comparatively, many measures of canopy structure - such as mean height, leaf area index, stem density, and diameter distribution-are more easily acquired using inventory or remote sensing approaches [13-17]. Because aboveground ecosystem structure is more easily characterized, identification of coupled above-and belowground structural features could advance and simplify efforts to infer root structure from canopy structure, and provide new opportunities to scale, model, and interpret root-canopy interactions.

Remote sensing, when used concurrently to characterize fine-scale above- and belowground structure, may provide a powerful tool for non-destructive characterization of root and canopy structure. Approaches successfully pairing geophysical data from ground penetrating radar (GPR) with canopy structural data derived from aerial LiDAR suggest parallel approaches could be applied to couple root and canopy structure $[18,19]$. One such non-destructive approach, ground-based portable canopy LiDAR (PCL), provides sub-meter estimates of leaf quantity and arrangement within canopies (Parker and Russ 2004, Hardiman et al. 2011) using high-frequency laser pulses. Similarly, GPR is used extensively to quantify and determine at comparable spatial scales the distribution of root biomass in upper soil horizons [20-24]. GPR relies on differential propagation of electromagnetic waves through the soil and uses travel time and amplitude of reflected signals to estimate biomass [20]. In this study, we demonstrate how PCL and GPR can be applied in tandem to explicitly couple fine-scale above- and belowground structure.

\section{Methods}

\subsection{Study Site and Layout}

Our study was conducted at the University of Michigan Biological Station (UMBS) in northern lower Michigan, USA, in a transitional zone between temperate and boreal forest $[25,26]$. The site contains ecosystems common throughout the region, which include secondary forests regrown during the last century following harvest and wildfire, and primary "old-growth" forest fragments that were spared stand-replacing disturbance [27]. Detailed descriptions of UMBS forests are found in [28-31].

For our analysis of above- and belowground structure, we selected three forest sites spanning a broad gradient in canopy structural complexity [30] (Figure 1A,B). An old-growth (age = 185 years) forest site, hereafter called "late succession", subject to infrequent single-tree harvesting during the middle 20th century containing several canopy gaps and a complex canopy structure $[30,32]$ was dominated by late successional eastern hemlock (Tsuga canadensis L.), American beech 
(Fagus grandifolia Ehrh.), northern red oak (Quercus rubra L.), and sugar maple (Acer saccharum Marsh.). A second forest site (age = 95 years), hereafter termed "middle succession", was transitioning from early to middle stages of ecological succession following clearcut harvesting and fire in the early 20th century [33]. Canopy composition includes a large but rapidly declining fraction of early successional aspen (Populus grandidentata Michx. and Populus tremuloides Michx.) and birch (Betula papyrifera Marsh.), with increasing representation in the canopy of northern red oak, red maple (A. rubrum L.), white pine (Pinus strobus L.), and American beech. Lastly, an early successional forest site (age $=31$ years) established in 1980 following clearcut harvesting and fire, hereafter referred to as "early successional", was dominated by a relatively uniform aspen and birch canopy [33].

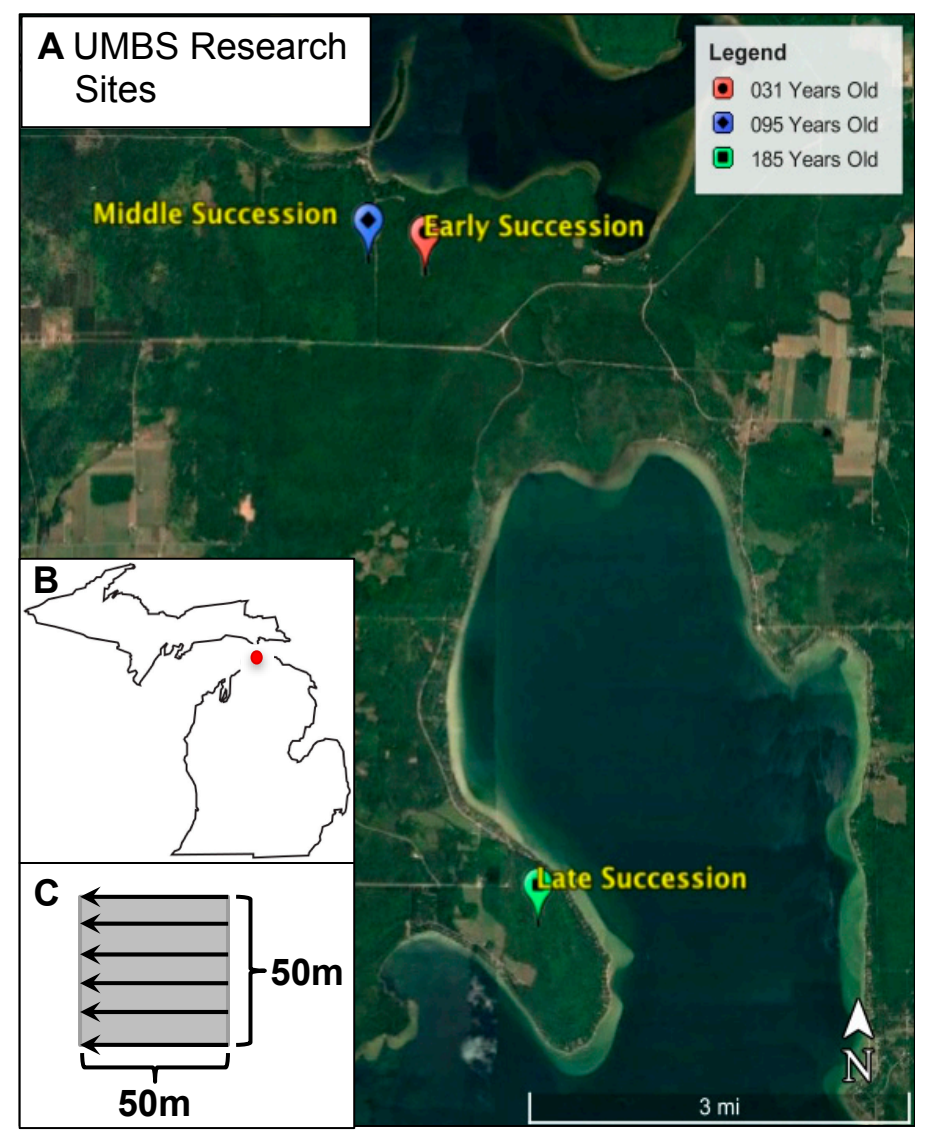

Figure 1. Research sites and sampling strategy. Location of early, middle, and late successional research sites (A) in Michigan ((B), red circle) with sampling design at each site (C), showing orientation and spacing of portable canopy LiDAR (PCL) and ground penetrating radar (GPR) transects (black arrows) within each $50 \mathrm{~m} \times 50 \mathrm{~m}(0.25 \mathrm{ha})$ plot (grey square).

Within each forest site, we remotely sensed above- (canopy) and belowground (root) structure (defined as the quantity and spatial distribution of biomass) at two spatial scales to assess structural variation within and across plots. Our 2010 sampling campaign characterized within-stand structural variability to identify the spatial scale of canopy and root structural coherence. We used GPR and PCL data to co-characterize high resolution root and canopy structure continuously along six parallel $50 \mathrm{~m}$ transects, each $10 \mathrm{~m}$ apart within $2500 \mathrm{~m}^{2}$ plots in early, middle, and late successional forests (Figure 1C). This design was chosen to allow examination of the spatial scale of root and canopy covariation at multiple scales. Upward-facing PCL and downward-facing GPR were both deployed along each $50 \mathrm{~m}$ transect to produce perfectly aligned data on spatial distribution of canopy and root biomass (Figure 2A,B). A second sampling campaign was a conventional qualitative comparison of canopy and root structural coherence. Fine-scale structure was characterized within six $2 \mathrm{~m} \times 2 \mathrm{~m}$ 
square subplots nested within early and late successional plots. In the early successional stand, 3 subplots were positioned under canopy gaps; no gaps were present in the late successional plot. Parallel transects (length $=2 \mathrm{~m}$ ) were established at $25-\mathrm{cm}$ spacing the width of the subplots. Root biomass was assessed by GPR along each transect $(n=9)$ while the PCL was deployed along alternating transects $(n=5)$ in each plot.

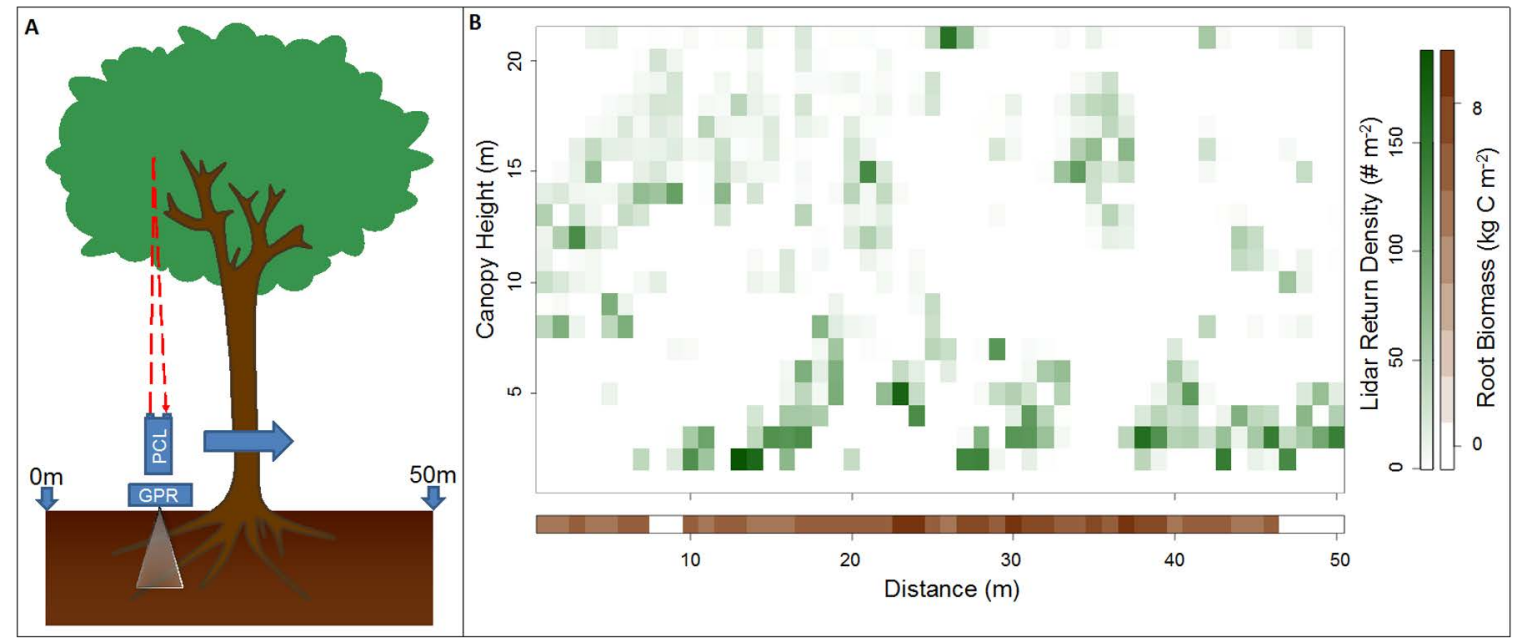

Figure 2. Conceptual and empirical illustrations of alignment of canopy and root structure data. (A) Colocated scans of canopy and root structure were collected using portable canopy LiDAR (PCL) and ground penetrating radar (GPR), respectively, along $50 \mathrm{~m}$ transects. Vertical cross-sections of canopy ((B) top) and root ((B) bottom) biomass distribution illustrating the arrangement of $50 \mathrm{~m} \mathrm{LiDAR}$ and radar data collected along the same transect (the example above is from the middle successional stand). LiDAR returns are binned to $1 \mathrm{~m}^{2}$ (horizontal and vertical) and radar returns are column totals binned to $1 \mathrm{~m}$ (horizontally). LiDAR bins are shaded proportionally to return density (correlated with canopy biomass) and radar bins are shaded proportionally to biomass (both shown on the vertical color bar on the right).

\subsection{Aboveground Canopy Structure: Portable Canopy LiDAR}

We characterized canopy structure using a PCL equipped with a near-infrared laser distance meter (model LD90-3100VHS-FLP; RieglUSA, Inc., Orlando, FL, USA). Design, operation, and validation of the PCL is described in detail elsewhere [29,30,34-36]. Briefly, the PCL is an upward-pointing ground based high-frequency laser distance meter that non-destructively measures vegetation height by reflecting laser pulses off canopy surfaces (Figure 2A). The PCL produces a vertical cross section of fine-scale canopy height and spatial distribution of canopy elements, permitting derivation of a suite of metrics characterizing height (maximum canopy height, height of maximum leaf density, mean height of canopy surfaces, etc.), variability of height metrics across the transect, and openness of the canopy volume (gap fraction, clumping index, and porosity) (Figure 2B). Additional explanation of the derivation and interpretation of these structural metrics can be found in Hardiman et al. [35]. Of the structural metrics derived from PCL, we compared mean canopy height with root structure because the former is readily acquired using ground surveys and airborne LiDAR measurements, making this accessible expression of aboveground structure an ideal candidate for examining links to belowground structures.

\subsection{Belowground Structure: Ground-Penetrating Radar}

We used GPR to estimate $1 \mathrm{~m}$ resolution quantity and distribution of lateral root biomass along the same survey transects used in the collection of PCL-based canopy data. Soils along transects were scanned with a SIR-3000 radar unit (Geophysical Survey Systems Inc. (GSSI), Salem, New Hampshire) 
equipped with a $1500 \mathrm{MHz}$ antenna and a measurement cart with an integrated survey wheel to measure distance traveled along the transect. As with the PCL, the design, operation, and validation of the GPR system is described extensively in prior publications [20,37] and has been successfully used to determine orientation, diameter, depth, and density of roots in situ [20,38-40]. Briefly, the GPR pulses electromagnetic energy into soils and records the two-way travel time of signals reflected from roots (Figure 2). We filtered noise in GPR images using RADAN 7 software (GSSI, Nashua, New Hampshire), determined root location and size with SigmaScan Pro Image Analysis software (Systat Software, Point Richmond, California), and quantified root biomass using the approach employed by Butnor et al. [39], summarized briefly here. The GPR system measures lateral roots and thus GPR-derived root biomass estimates do not include roots directly beneath stems/stumps [37]. GPR estimates of root biomass were calibrated using 30 soil cores collected from each of the three forest plots. Each location was scanned at the surface using GPR prior to excavation to $45-\mathrm{cm}$ depth with a $15-\mathrm{cm}$ diameter stovepipe. Soils were dry-sieved to extract roots, which were then washed, oven-dried at $65^{\circ} \mathrm{C}$ to a constant mass, weighed to determine dry mass, and then converted to carbon mass using a site-specific carbon fraction of 0.48 [33]. Correlation coefficients between GPR and observed root mass ranged from $r=0.68$ to $r=0.77$ among forest sites. GPR-derived estimates of column-total root biomass were compared to PCL estimates of canopy height.

\subsection{Wavelet Coherence Analysis}

Our field data collection yielded detailed $1 \mathrm{~m}$ resolution canopy and root structural information (Figure 2), which we examined for coherence at multiple spatial scales $\leq 10 \mathrm{~m}$ within each site using wavelet analysis [41] conducted with the Grinsted [42] Matlab wavelet toolbox. Because our goal was to identify and characterize potential linkages between aboveground and belowground structural features, we focused our wavelet analysis on structural measures that are readily derived from PCL and GPR data and, in the case of aboveground structure, easily obtained using other (e.g., inventory based) approaches. Wavelets decompose the variability of a spatial process on a scale-base function. Wavelet coherence (WC) of two spatial patterns, $X$ and $Y$, is calculated as

$$
W C(s)=\frac{\left|C_{X Y}(s)\right|^{2}}{S_{X X}(s) S_{Y Y}(s)}
$$

where $S_{X X}$ and $S_{Y Y}$ are the univariate global wavelet spectra of spatial pattern $X$ and $Y$, respectively, at scale $s$, and $C_{X Y}$ is their global wavelet cospectrum [42]. Wavelet coherence is a standardized measurement of the wavelet covariance similar to a Pearson correlation coefficient, and is bounded between 0 , signifying that two spatial patterns never co-occur, and 1 signifying perfect co-occurrence.

Given our interest in fine-scale $(\leq 10 \mathrm{~m})$ root-canopy structural correspondence, we evaluated coherence at scales of 1.5 to $10 \mathrm{~m}$ using a Morlet wavelet function. Additionally, the evaluation of scales $>10 \mathrm{~m}$ along our $50 \mathrm{~m}$ transects would reduce the number of replicates to $<5$ per transect, greatly decreasing statistical power to detect coherence. The ensemble wavelet coherence was computed for each site as the average of wavelet coherences of the six transects within each site. Confidence intervals (CIs) were computed using 1000 random combinations of GPR and LiDAR-derived canopy height of the six transects for each site. To increase the number of permutations considered when generating CIs, we also included flipped (reversed) transects.

\section{Results}

\subsection{Canopy and Root Vertical Structure}

We observed substantial differences among sites in mean vertical canopy and root structure, with leaf area density (LAD) and root mass more evenly distributed by height and depth, respectively, as forests aged. The vertical distribution of vegetation in the canopy, expressed as LAI, became increasingly more even as forests got older, indicating a progressive advance to a taller and more 
multi-layered canopy (Figure 3A). The early successional forest canopy was $15 \mathrm{~m}$ tall and exhibited a unimodal distribution, with a dense LAI layer at $\sim 10 \mathrm{~m}$. In the middle successional forest, maximum height was $22 \mathrm{~m}$, with a broadly bimodal vertical LAI distribution; an LAI peak at $18 \mathrm{~m}$ indicated a concentration of canopy dominant trees, and a second peak at $\sim 5 \mathrm{~m}$ signified a substantial subcanopy stratum. Maximum canopy height of the late successional forest was $28 \mathrm{~m}$ and LAD was relatively uniform across heights.
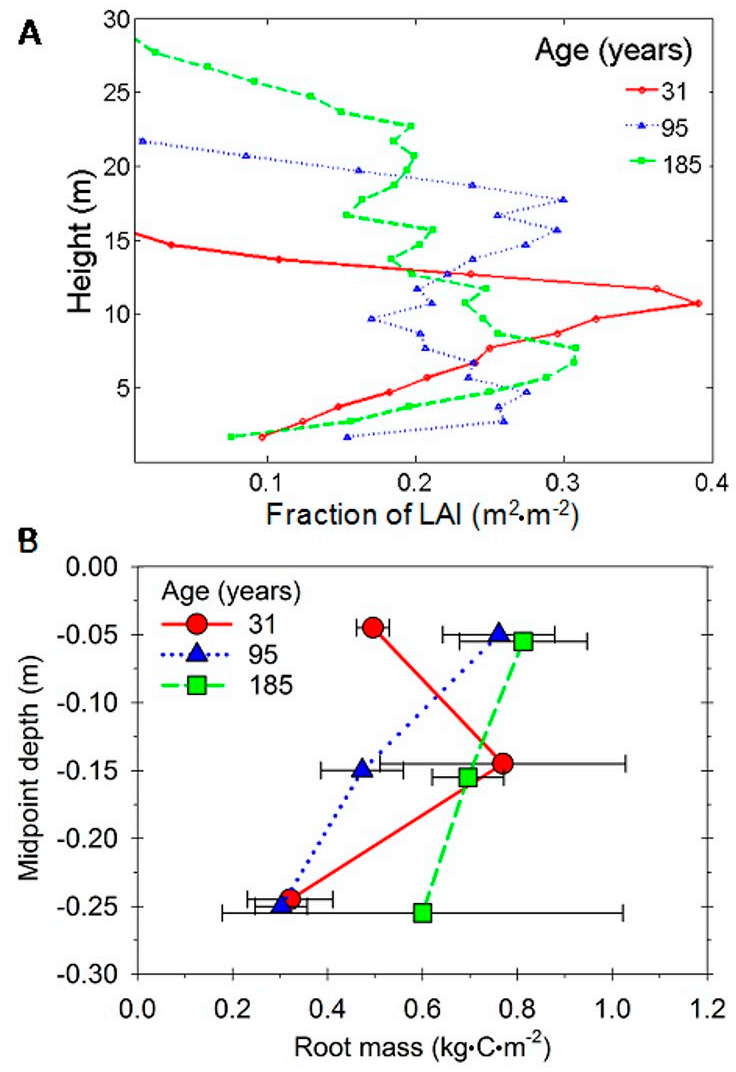

Figure 3. Canopy and root vertical profiles. Vertical profiles of canopy and root biomass change with stand age demonstrating greater vertical uniformity in older stands. Canopy height increases with stand age and biomass distribution becomes more uniform (A). Mean root biomass $( \pm \mathrm{SE})$ increases in deeper soil horizons as stands age, but younger forests exhibit highest root biomass at moderate depths (B).

Root mass exhibited similar trends of increasing vertical evenness with increasing age (Figure 3B). Root mass was irregularly distributed across soil depths in the early successional forest, becoming more uniform in older forests. Peak root mass in the youngest forest was concentrated at $15 \mathrm{~cm}$ (midpoint) and at the soil surface in the two older forests. In middle successional forests, root mass decreased significantly $(p<0.05)$ with increasing soil depth. The middle successional forest had the broadest range of root mass across depths, while root mass in late successional forest did not differ significantly across soil depths.

\subsection{Canopy and Root Structural Coherence across Ecosystem Development}

We found that canopy and root structure were significantly related at all stages of forest development, but that the strength and statistical significance of this coherence was dependent upon the spatial scale of comparison. In our wavelet coherence analysis, we focused on the correlation of two structural parameters derived from PCL and GPR: maximum canopy height and root mass, respectively. Our findings indicate that at a scale of 3.5-4 $\mathrm{m}$, the frequencies of variation in canopy height and root 
biomass were significantly coherent (WC $=\sim 0.3, p<0.05$ ) in all stages of forest development, increasing slightly with age (Figure 4). These results indicate subtle differences across forest development in the spatial scale but not strength of coherence between maximum canopy height and root mass. Canopy height and root mass were additionally coherent in the oldest and most structurally complex stand at $\sim 8 \mathrm{~m}$ (WC $=\sim 0.6, p<0.05$ ). Root-canopy structural coherence was not significant at any other spatial scales examined $(p>0.05)$.

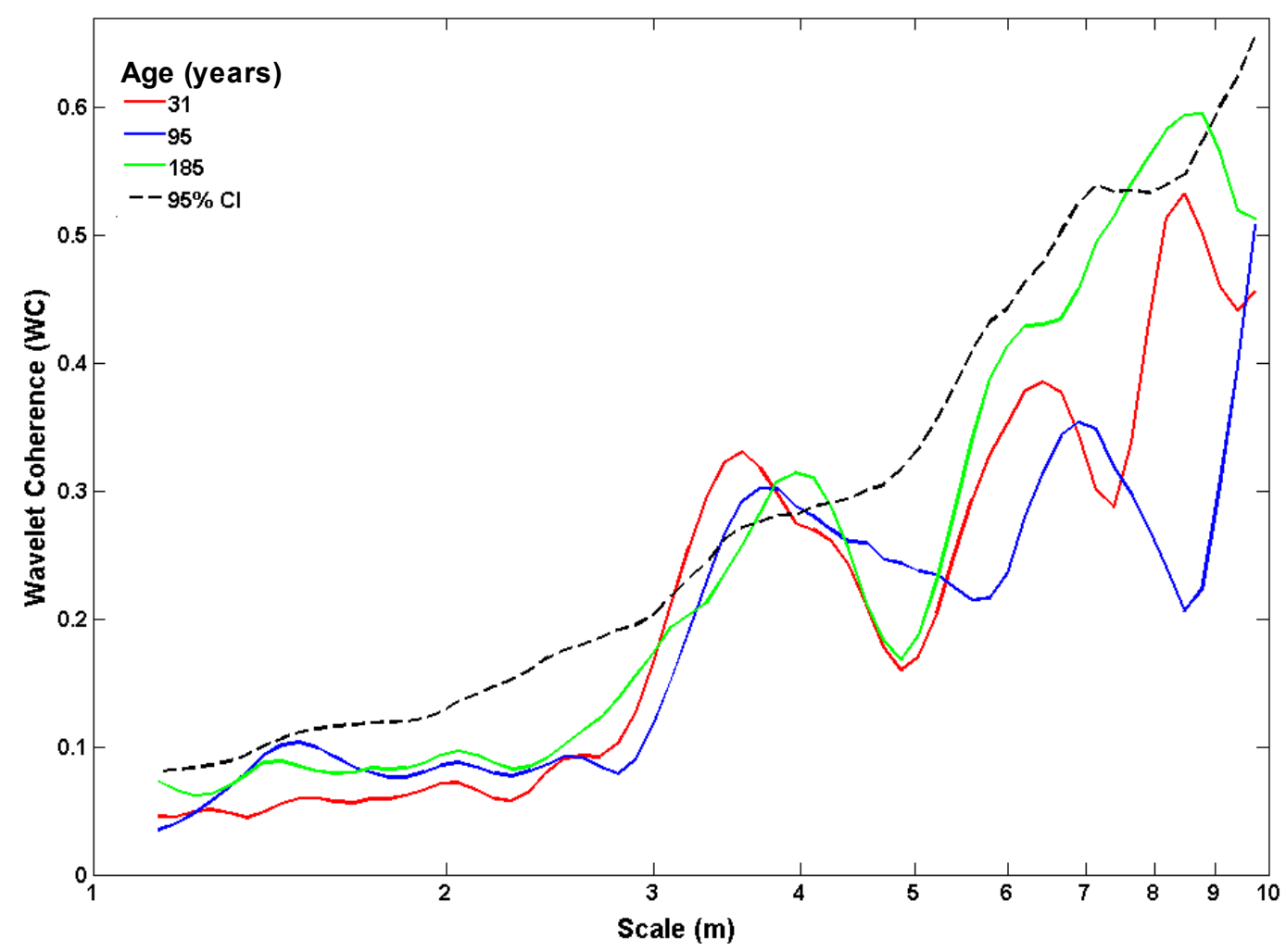

Figure 4. Roots and canopy structural coherence. Wavelet coherence between canopy height and root biomass peaks in all stands at 3-4 $\mathrm{m}$ and again at $8 \mathrm{~m}$ in the oldest stand. Each line is an average across all six transects in each stand. Confidence intervals were constructed from 1000 randomizations of six random samples independently extracted from the dataset pooled across sites. Portions of each curve above the dotted line indicate scales at which root biomass and canopy height are significantly coherent. Note that the $\mathrm{x}$-axis is a shown on a log scale.

\subsection{Small-Scale Canopy and Root Structural Correspondence}

We evaluated root-canopy structural coherence using conventional approaches that examine root mass below continuous canopy cover or gaps. Our analysis showed root mass was weakly related to the visually determined occurrence of small canopy gaps in the youngest forest, a finding consistent with our wavelet coherence analysis revealing limitations in the detection of canopy and root structural correspondence when data were binned at arbitrarily small $(<3 \mathrm{~m})$ spatial scales. Similarly, we observed no significant difference in the youngest stand in root mass below small $\left(2 \mathrm{~m}^{2}\right)$ canopy gaps and intact canopies (Figure 5, $p>0.05$ ). Canopy gaps were absent in the oldest stand but stem density was lowest of the three and fine-scale GPR estimates of root biomass under continuous canopy were significantly lower than in the youngest stand. This finding reinforces our wavelet coherence results indicating that root and canopy structural coherence and, by extension, the capacity to infer root structure from canopy structure is scale-dependent. 


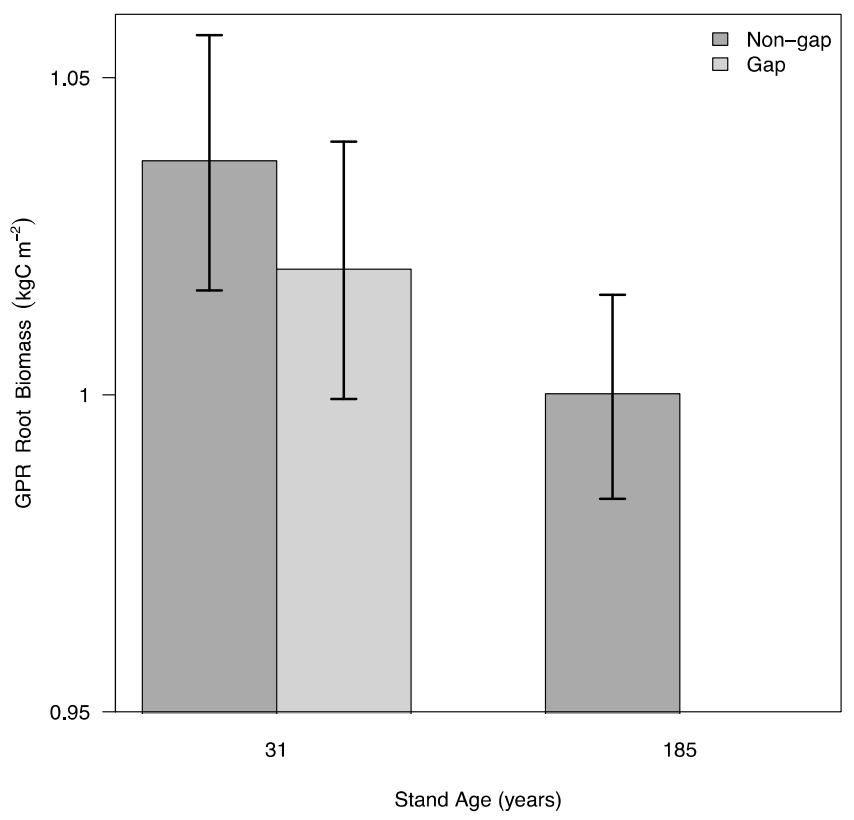

Figure 5. Influence of canopy gaps and stand age on root biomass. Fine-scale mean ( $\pm 95 \%$ confidence intervals) GPR-derived root biomass changes with stand age and disturbance as measured by $2 \mathrm{~m}$ GPR transects in subplots located under gaps or continuous canopies. No gaps were present in the 185-year-old stand.

\section{Discussion}

Our findings indicate simple measures of canopy structure, such as maximum canopy height, obtained using remote sensing and inventory approaches, are related to fine-scale root mass and the distribution thereof, but that the degree of coherence between root and canopy structure is scale- and, to a lesser extent, ecosystem-dependent. We found peak correspondence between maximum canopy height and root mass occurred in all stands when data were aligned at a spatial scale of 3.5-4 m, with the scale of peak correspondence increasing slightly (by $0.25 \mathrm{~m}$ ) from one stage of ecosystem development to the next. More generally, this finding indicates that the strength of canopy-root coupling is sensitive to the spatial scale at which these structures are measured (Figure 4), and may explain why qualitative assessments of canopy-root structural coherence conducted at a variety of spatial scales, including ours (Figure 5), report mixed degrees of canopy-root coupling (e.g., $[7,8])$. The spatial scale (3.5-4 m) of maximum canopy-root structural correspondence at our sites may approximate the average individual-tree biomass footprint, which generally increases above- and belowground with forest age. For example, mean tree crown length, stem diameter, and root length increased with age in a number of different ecosystems [1,43-46]. A second scale of significant coherence at $8 \mathrm{~m}$ in the oldest stand is a signal of high variation in individual-tree footprint size within this complex late successional forest, which contains a mosaic of smaller closely-spaced trees and larger mature trees spaced farther apart; in contrast, the younger stands have one primary canopy layer comprised of geometrically less variable trees and, therefore, more uniform in biomass footprint size (Figure 4, Table 1; [35,37]).

Table 1. Stand characteristics. All values are means (standard error) for each study site.

\begin{tabular}{|c|c|c|c|c|}
\hline Stand & Age (years) & Stem Density (trees $\cdot \mathrm{ha}^{-1}$ ) & $\operatorname{LAI}\left(\mathrm{m}^{2} \cdot \mathrm{m}^{-2}\right)$ & $\operatorname{AGB}\left(\mathrm{MgC} \cdot \mathrm{ha}^{-1}\right)$ \\
\hline Early Succession & $31^{\mathrm{a}}$ & $6047(938)^{a}$ & $3.0(\mathrm{na})^{\mathrm{a}}$ & $76(6.4)^{b}$ \\
\hline Middle Succession & $95^{\mathrm{a}}$ & $714(29)^{a}$ & $3.7(0.3)^{c}$ & $94.2(3.4)^{\mathrm{d}}$ \\
\hline Late Succession & $185^{c}$ & $433\left(\right.$ na) ${ }^{e}$ & $5.3(0.4)^{\mathrm{c}}$ & $461(15.6)^{b}$ \\
\hline
\end{tabular}

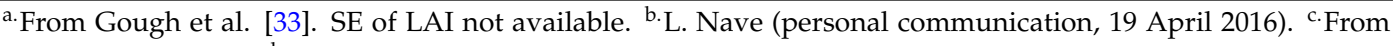
Hardiman et al. [30]. d. From Gough et al. [47]. e. From Liebman et al. [48]. 
More broadly, the definition of "structure" used when looking for potential relationships between canopy and root structures may influence the likelihood of detecting them, but this is unknown. Many definitions of "structure" exist in the literature (see [49] for an example of disambiguation of canopy structural terms), and there are many metrics that quantify it. While a full evaluation of the myriad metrics of structure present in the literature is beyond the scope of this study, our analysis using one very simple metric each of canopy and root structure (mean canopy height and root biomass, respectively, both measured continuously along a transect) was sufficient to identify significant relationships between above and belowground structures. This suggests that these results are robust, though future investigations should explore additional metrics.

While the scale-dependency of canopy-root correlation indicates caution must be exercised when interpreting canopy and root structural linkages, the range and distribution of spatial scales (3.5-4 m, $8 \mathrm{~m}$ in oldest forest) in which above/belowground structure was significantly coherent at our sites was narrow considering the comparatively large differences across ecosystem development in canopy and root vertical structure $[38,50]$. Moreover, the increasing scale of root-canopy structural coherence and transition from unimodal to bimodal correspondence with age is consistent with ecological understanding of changes in complexity over the course of forest development [38]. Nonetheless, inferring root structure from canopy structure in other, particularly non-forested, ecosystems requires understanding of scale-dependencies across a much broader array of plant growth forms and spatial densities, factors which affect ecosystem physical structure, and the quantity and allocation of above- and belowground biomass [51,52].

Ground and airborne LiDAR approaches to remotely sensing canopy structure, including canopy height, are well developed [15,50,53-55], but are rarely coupled with GPR approaches for remotely sensing root structure $[41,42,56,57]$. Airborne LiDAR data products alone have been used to quantify root mass at sub-hectare $(>30 \mathrm{~m})$ spatial scales in boreal and subtropical forests [58,59], and to scale GPR-based root mass in an oak savanna [21], highlighting potential for joining LiDAR and radar technologies to more comprehensively quantify and couple above- and belowground ecosystem structure. Our findings build on and advance these prior results by showing that remote sensing applications of coupled ground-based LiDAR and ground penetrating radar, which both operate at finer spatial scales, may provide an order of magnitude higher $(<10 \mathrm{~m})$ resolution. High resolution, non-destructive co-quantification of canopy and root structure could be used to infer and interpret ecosystem functions requiring understanding of fine-scale structure, including primary production $[30,60]$, animal habitat suitability and diversity $[61,62]$, and tree-scale hydrologic processes [21,63].

Ground-based approaches for remotely sensing ecosystem structure have been applied successfully to variety of ecosystems, but LiDAR and radar-based methods have limitations that may preclude the derivation of robust co-located above- and belowground measurements under some conditions. A comprehensive review of LiDAR and radar ecological applications and limitations is beyond the scope of this study and is available elsewhere $[15,41,50]$; here, we briefly summarize current limitations of each technology. Accurate characterization of canopy structure, especially metrics based on height, relies on accurate sampling of the full depth of the canopy volume. Areas of especially dense leaf area can occlude the laser beam emitted from the PCL system, a problem common to optical remote sensing methods $[15,50,64,65]$, constraining inference of distribution of canopy elements above such areas. Multireturn and waveform LiDAR have improved the penetration ability of the laser beam, but these techniques have been usually deployed on airborne platforms (e.g., [48]), and applied to large scale monitoring programs with high operational costs [66]. Similarly, signal propagation from the GPR system though the vertical soil profile similarly diminishes with depth, meaning the lower extent of sampled soil volume is poorly defined. This may limit applications to water-limited ecosystems, where root systems extend deeply into the soil. Further, GPR resolution is such that bundles of fine roots can appear as a single large root, while individual fine roots challenge detection 
limits; discontinuities of soil moisture and/or texture can also contribute noise [40,41], which can be minimized with rigorous site-specific calibration of the GPR using conventional root coring methods.

\section{Conclusions}

We have shown that portable canopy LiDAR and ground penetrating radar, when paired, can yield quantitative and potentially scalable coupled canopy-root structural information. While this study conclusively demonstrates that root biomass is related to canopy structure, and puts bounds on the spatial scale of that relationship, knowledge of the precise location of that root biomass remains imprecise in this analysis. The ability to estimate the quantity and spatial arrangement of root biomass using aboveground structural features is a compelling goal and the analysis presented in this study is an important step in that direction. Future studies can focus on refining these methods to develop quantitative predictive models of root biomass quantity and location from canopy structural features.

Moving forward, we suggest fundamental understanding of fine-scale canopy-root linkages can be advanced through improvements in remote sensing technology and through systematic quantitative evaluations of above- and belowground structure for a broad array of ecosystems. Presently, generalized quantitative understanding of coupled canopy-root structure is limited by a prior emphasis on largely qualitative comparisons and, in quantitative studies, substantial unexplained variation among ecosystems in above- and belowground biomass allocation patterns owing in part to variable study approaches, arbitrary scales of analysis, and sampling challenges [51,52]. Widespread systematic and coordinated quantification of above- and belowground ecosystem structure, for example by ecological networks [67,68], could transform basic biological understanding of small-scale canopy-root linkages, and lead to advances in interpreting and predicting an array of ecosystem functions dependent upon both above- and belowground structure.

Acknowledgments: We wish to thank Lucas Nave, Alex Fotis, and Conor Flynn for assistance in quantifying root biomass. We acknowledge the University of Michigan Biological Station for facilities and material support. This work was supported in part by U.S. Department of Energy's Office of Science, Office of Biological and Environmental Research, Ameriflux Management project under Flux Core Site agreement No. 7096915 through Lawrence Berkeley National Laboratory.

Author Contributions: All authors made substantial original intellectual contributions to the collection and analysis of data described in this study and have reviewed and approved the final manuscript prior to submission. The work described in the manuscript is the authors' own original work and has not been published previously, nor is it under consideration for publication elsewhere.

Conflicts of Interest: The authors declare no conflicts of interest, financial, personal, or otherwise.

\section{References}

1. Monserud, R.A.; Sterba, H. A basal area increment model for individual trees growing in even- and uneven-aged forest stands in Austria. For. Ecol. Manag. 1996, 80, 57-80. [CrossRef]

2. Medvigy, D.; Wofsy, S.C.; Munger, J.W.; Hollinger, D.Y.; Moorcroft, P.R. Mechanistic scaling of ecosystem function and dynamics in space and time: Ecosystem Demography model version 2. J. Geophys. Res. 2009, 114, 1-21. [CrossRef]

3. Reich, P.B. Key canopy traits drive forest productivity. Proc. R. Soc. B Biol. Sci. 2012, 279, $2128-2134$. [CrossRef] [PubMed]

4. Parsons, W.F.J.; Knight, D.H.; Miller, S.L. Root gap dynamics in lodgepole pine forest: Nitrogen transformations in gaps of different size. Ecol. Appl. 2016, 4, 354-362. [CrossRef]

5. Ritter, E.; Starr, M.; Vesterdal, L. Losses of nitrate from gaps of different sizes in a managed beech (Fagus sylvatica) forest. Can. J. For. Res. 2005, 35, 308-319. [CrossRef]

6. Shachnovich, Y.; Berliner, P.R.; Bar, P. Rainfall interception and spatial distribution of throughfall in a pine forest planted in an arid zone. J. Hydrol. 2008, 349, 168-177. [CrossRef]

7. Ostertag, R. Belowground effects of canopy gaps in a tropical wet forest. Ecology 1998, 79, $1294-1304$. [CrossRef] 
8. McGuire, J.P.; Mitchell, R.J.; Moser, E.B.; Pecot, S.D.; Gjerstad, D.H.; Hedman, C.W. Gaps in a gappy forest: Plant resources, longleaf pine regeneration, and understory response to tree removal in longleaf pine savannas. Can. J. For. Res. 2001, 31, 765-778. [CrossRef]

9. Purbopuspito, J.; Van Rees, K.C.J. Root distribution at various distances from clove trees growing in Indonesia. Plant Soil 2002, 239, 313-320. [CrossRef]

10. Taskinen, O.; Ilvesniemi, H.; Kuuluvainen, T.; Leinonen, K. Response of fine roots to an experimental gap in a boreal Picea abies forest. Plant Soil 2003, 255, 503-512. [CrossRef]

11. Schroeer, A.E.; Hendrick, R.L.; Harrington, T.B. Root, ground cover, and litterfall dynamics within canopy gaps in a slash pine (Pinus elliottii Engelm.) dominated forest. Ecoscience 1999, 6, 548-555. [CrossRef]

12. Johnson, M.G.; Tingey, D.T.; Phillips, D.L.; Storm, M.J. Advancing fine root research with minirhizotrons. Environ. Exp. Bot. 2001, 45, 263-289. [CrossRef]

13. Lefsky, M.A.; Harding, D.; Cohen, W.B.; Parker, G.G.; Shugart, H.H. Surface LiDAR remote sensing of basal area and biomass in deciduous forests of eastern Maryland, USA. Remote Sens. Environ. 1999, 67, 83-98. [CrossRef]

14. Lefsky, M.A.; Cohen, W.B.; Harding, D.J.; Parker, G.G.; Acker, S.A.; Gower, S.T. LiDAR remote sensing of above-ground biomass in three biomes. Glob. Ecol. Biogeogr. 2002, 11, 393-399. [CrossRef]

15. Lefsky, M.A.; Cohen, W.B.; Parker, G.G.; David, J. LiDAR remote sensing for ecosystem studies. Bioscience 2002, 52, 19-30. [CrossRef]

16. Gonzalez, P.; Asner, G.P.; Battles, J.J.; Lefsky, M.A.; Waring, K.M.; Palace, M. Forest carbon densities and uncertainties from LiDAR, QuickBird, and field measurements in California. Remote Sens. Environ. 2010, 114, 1561-1575. [CrossRef]

17. Garrity, S.R.; Meyer, K.; Maurer, K.D.; Hardiman, B.S.; Bohrer, G. Estimating plot-level tree structure in a deciduous forest by combining allometric equations, spatial wavelet analysis and airborne LiDAR. Remote Sens. Lett. 2012, 3, 443-451. [CrossRef]

18. Roering, J.J.; Marshall, J.; Booth, A.M.; Mort, M.; Jin, Q. Evidence for biotic controls on topography and soil production. Earth Planet. Sci. Lett. 2010, 298, 183-190. [CrossRef]

19. Hubbard, S.S.; Gangodagamage, C.; Dafflon, B.; Wainwright, H.; Peterson, J.; Gusmeroli, A.; Ulrich, C.; $\mathrm{Wu}, \mathrm{Y}$; Wilson, C.; et al. Quantifying and relating land-surface and subsurface variability in permafrost environments using LiDAR and surface geophysical datasets. Hydrogeol. J. 2012, 21, 149-169. [CrossRef]

20. Butnor, J.R.; Doolittle, J.A.; Johnsen, K.H.; Samuelson, L.; Stokes, T.; Kress, L. Utility of Ground-Penetrating Radar as a Root Biomass Survey Tool in Forest Systems. Soil Sci. Soc. Am. J. 2003, 67, 1607-1615. [CrossRef]

21. Yaseef, N.R.; Koteen, L.; Baldocchi, D.D. Coarse root distribution of a semi-arid oak savanna estimated with ground penetrating radar. J. Geophys. Res. Biogeosci. 2013, 118, 135-147. [CrossRef]

22. Hruska, J.; Cermák, J.; Sustek, S. Mapping tree root systems with ground-penetrating radar. Tree Physiol. 1999, 19, 125-130. [CrossRef] [PubMed]

23. Barton, C.V.M.; Montagu, K.D. Detection of tree roots and determination of root diameters by ground penetrating radar under optimal conditions. Tree Physiol. 2004, 24, 1323-1331. [CrossRef] [PubMed]

24. Samuelson, L.J.; Stokes, T.A.; Butnor, J.R.; Johnsen, K.H.; Gonzalez-benecke, C.A.; Anderson, P.; Jackson, J.; Ferrari, L.; Martin, T.A.; Cropper, W.P. Ecosystem carbon stocks in Pinus palustris forests. Can. J. For. Res. 2014, 486, 476-486. [CrossRef]

25. Nave, L.E.; Sparks, J.P.; Le Moine, J.; Hardiman, B.S.; Nadelhoffer, K.J.; Tallant, J.M.; Vogel, C.S.; Strahm, B.D.; Curtis, P.S. Changes in soil nitrogen cycling in a northern temperate forest ecosystem during succession. Biogeochemistry 2014, 121, 471-788. [CrossRef]

26. Schmid, H.P.; Su, H.B.; Vogel, C.S.; Curtis, P.S. Ecosystem-atmosphere exchange of carbon dioxide over a mixed hardwood forest in northern lower Michigan. J. Geophys. Res. 2003, 108. [CrossRef]

27. Gough, C.M.; Curtis, P.S.; Hardiman, B.S.; Scheuermann, C.; Lamberty, B.B. Disturbance, complexity, and succession of net ecosystem production in North America's temperate deciduous forests. Ecosphere 2016, 7. [CrossRef]

28. Gough, C.M.; Vogel, C.S.; Hardiman, B.; Curtis, P.S. Wood net primary production resilience in an unmanaged forest transitioning from early to middle succession. For. Ecol. Manag. 2010, 260, 36-41. [CrossRef]

29. Gough, C.M.; Hardiman, B.S.; Nave, L.E.; Bohrer, G.; Maurer, K.D.; Vogel, C.S.; Nadelhoffer, K.J.; Curtis, P.S. Sustained carbon uptake and storage following moderate disturbance in a Great Lakes forest. Ecol. Appl. 2013, 23, 1202-1215. [CrossRef] [PubMed] 
30. Hardiman, B.S.; Gough, C.M.; Halperin, A.; Hofmeister, K.L.; Nave, L.E.; Bohrer, G.; Curtis, P.S. Maintaining high rates of carbon storage in old forests: A mechanism linking canopy structure to forest function. For. Ecol. Manag. 2013, 298, 111-119. [CrossRef]

31. Nave, L.E.; Gough, C.M.; Maurer, K.D.D.; Bohrer, G.; Hardiman, B.S.; Le Moine, J.; Munoz, A.B.; Nadelhoffer, K.J.; Sparks, J.P.; Strahm, B.D.; et al. Disturbance and the resilience of coupled carbon and nitrogen cycling in a north temperate forest. J. Geophys. Res. 2011, 116. [CrossRef]

32. Albert, D.A.; Minc, L.D. The Natural Ecology and Cultural History of the Colonial Point Red Oak Stands; University of Michigan Biological Station: Pellston, MI, USA, 1987.

33. Gough, C.M.; Vogel, C.S.; Harrold, K.H.; George, K.; Curtis, P.S. The legacy of harvest and fire on ecosystem carbon storage in a north temperate forest. Glob. Chang. Biol. 2007, 13, 1935-1949. [CrossRef]

34. Fahey, R.; Fotis, A.T.; Woods, K.D. Quantifying canopy complexity and effects on productivity and resilience in late successional hemlock-hardwood forests. Ecol. Appl. 2014, 25, 834-847. [CrossRef]

35. Hardiman, B.S.; Bohrer, G.; Gough, C.M.; Curtis, P.S. Canopy structural changes following widespread mortality of canopy dominant trees. Forests 2013, 4, 537-552. [CrossRef]

36. Parker, G.G.; Russ, M.E. The canopy surface and stand development: Assessing forest canopy structure and complexity with near-surface altimetry. For. Ecol. Manag. 2004, 189, 307-315. [CrossRef]

37. Butnor, J.R.; Samuelson, L.J.; Stokes, T.A.; Johnsen, K.H.; Anderson, P.H.; González-Benecke, C.A. Surface-based GPR underestimates below-stump root biomass. Plant Soil 2016, 402, 47-62. [CrossRef]

38. Butnor, J.R.; Doolittle, J.A.; Kress, L.; Cohen, S.; Johnsen, K.H. Use of ground-penetrating radar to study tree roots in the southeastern United States. Tree Physiol. 2001, 21, 1269-1278. [CrossRef] [PubMed]

39. Butnor, J.R.; Barton, C.; Day, F.P.; Johnsen, K.H.; Mucciardi, A.N.; Schroeder, R.; Stover, D.B. Using ground-penetrating radar to detect tree roots and estimate biomass. In Measuring Roots: An Updated Approach; Mancuso, S., Ed.; Springer Science \& Business Media: Berlin, Germany, 2012; p. 397.

40. Stover, D.B.; Day, F.P.; Butnor, J.R.; Drake, B.G. Effect of elevated $\mathrm{CO}_{2}$ on coarse-root biomass in Florida scrub detected by ground-penetrating radar. Ecology 2007, 88, 1328-1334. [CrossRef] [PubMed]

41. Kumar, P.; Georgiou, E.F. Wavelet analysis for geophysical applications. Rev. Geophys. 1997, 35, $385-412$. [CrossRef]

42. Grinsted, A.; Moore, J.C.; Jevrejeva, S. Application of the cross wavelet transform and wavelet coherence to geophysical time series. Nonlinear Process. Geophys. 2004, 11, 561-566. [CrossRef]

43. Watson, A.; O'Loughlin, C. Structural root morphology and biomass of three age-classes of Pinus radiata. N. Z. J. For. Sci. 1990, 20, 97-110.

44. Medhurst, J.L.; Battaglia, M.; Cherry, M.L.; Hunt, M.A.; White, D.A.; Beadle, C.L. Allometric relationships for Eucalyptus nitens (Deane and Maiden) Maiden plantations. Trees Struct. Funct. 1999, 14, 91-101. [CrossRef]

45. Wirth, C.; Schumacher, J.; Schulze, E.D. Generic biomass functions for Norway spruce in Central Europe-A meta-analysis approach toward prediction and uncertainty estimation. Tree Physiol. 2004, 24, 121-139. [CrossRef] [PubMed]

46. Børja, I.; de Wit, H.A.; Steffenrem, A.; Majdi, H. Stand age and fine root biomass, distribution and morphology in a Norway spruce chronosequence in southeast Norway. Tree Physiol. 2008, 28, 773-784. [CrossRef] [PubMed]

47. Gough, C.M.; Vogel, C.S.; Schmid, H.P.; Curtis, P.S. Controls on annual forest carbon storage: Lessons from the past and predictions for the future. Bioscience 2008, 58, 609-622. [CrossRef]

48. Liebman, E.; Yang, J.; Nave, L.; Nadelhoffer, K.; Gough, C. Soil respiration in upper Great Lakes old-growth forest ecosystems. BIOS 2017, in press.

49. Parker, G.G.; Brown, M.J. Forest canopy stratification-Is it useful?t Am. Nat. 2000, 155, 473-484. [PubMed]

50. Parker, G.G.; Harding, D.J.; Berger, M.L. A portable LiDAR system for rapid determination of forest canopy structure. J. Appl. Ecol. 2004, 41, 755-767. [CrossRef]

51. Mokany, K.; Raison, R.J.; Prokushkin, A.S. Critical analysis of root: Shoot ratios in terrestrial biomes. Glob. Chang. Biol. 2006, 12, 84-96. [CrossRef]

52. Poorter, H.; Niklas, K.J.; Reich, P.B.; Oleksyn, J.; Poot, P.; Mommer, L. Biomass allocation to leaves, stems and roots: Meta-analyses of interspecific variation and environmental control. New Phytol. 2012, 193, 30-50. [CrossRef] [PubMed]

53. Nelson, R.; Parker, G.; Hom, M. A portable airborne laser system for forest inventory. Photogramm. Eng. Remote Sens. 2003, 69, 267-273. [CrossRef] 
54. Lim, K.; Treitz, P.M.; Wulder, M.A.; St-Onge, B.; Flood, M. LiDAR remote sensing of forest structure. Prog. Phys. Geogr. 2003, 27, 88-106. [CrossRef]

55. Detto, M.; Asner, G.P.; Landau, H.C.M.; Sonnentag, O. Spatial variability in tropical forest leaf area density from Multireturn LiDAR and modelling. J. Geophys. Res. Biogeosci. 2015, 120, 1-16. [CrossRef]

56. Borden, K.A.; Isaac, M.E.; Thevathasan, N.V.; Gordon, A.M.; Thomas, S.C. Estimating coarse root biomass with ground penetrating radar in a tree-based intercropping system. Agrofor. Syst. 2014, 88, 657-669. [CrossRef]

57. Guo, L.; Chen, J.; Cui, X.; Fan, B.; Lin, H. Application of ground penetrating radar for coarse root detection and quantification: A review. Plant Soil 2013, 362, 1-23. [CrossRef]

58. Cao, L.; Coops, N.C.; Hermosilla, T.; Innes, J.; Dai, J.; She, G. Using small-footprint discrete and full-waveform airborne LiDAR metrics to estimate total biomass and biomass components in subtropical forests. Remote Sens. 2014, 6, 7110-7135. [CrossRef]

59. Kristensen, T.; Naesset, E.; Ohlson, M.; Bolstad, P.V.; Kolka, R. Mapping above- and below-ground carbon pools in boreal forests: The case for airborne lidar. PLoS ONE 2015, 10, 1-24. [CrossRef] [PubMed]

60. Hardiman, B.S.; Bohrer, G.; Gough, C.M.; Vogel, C.S.; Curtis, P.S. The role of canopy structural complexity in wood net primary production of a maturing northern deciduous forest. Ecology 2011, 92, 1818-1827. [CrossRef]

61. Goetz, S.; Steinberg, D.; Dubayah, R.; Blair, B. Laser remote sensing of canopy habitat heterogeneity as a predictor of bird species richness in an eastern temperate forest, USA. Remote Sens. Environ. 2007, 108, 254-263. [CrossRef]

62. Vierling, K.T.; Vierling, L.A.; Gould, W.A.; Martinuzzi, S.; Clawges, R.M. Lidar: Shedding new light on habitat characterization and modeling. Front. Ecol. Environ. 2008, 6, 90-98. [CrossRef]

63. Kirchner, J.W. Getting the right answers for the right reasons: Linking measurements, analyses, and models to advance the science of hydrology. Water Resour. Res. 2006, 42, 1-5. [CrossRef]

64. Côté, J.F.; Fournier, R.A.; Frazer, G.W.; Niemann, K.O. A fine-scale architectural model of trees to enhance LiDAR-derived measurements of forest canopy structure. Agric. For. Meteorol. 2012, 166, 72-85. [CrossRef]

65. Clawges, R.; Vierling, L.; Calhoon, M.; Toomey, M. Use of a ground-based scanning LiDAR for estimation of biophysical properties of western larch (Larix occidentalis). Int. J. Remote Sens. 2007, 28, 4331-4344. [CrossRef]

66. Asner, G.P.; Knapp, D.E.; Boardman, J.; Green, R.O.; Bowdoin, T.K.; Eastwood, M.; Martin, R.E.; Anderson, C.; Field, C.B. Carnegie Airborne Observatory-2: Increasing science data dimensionality via high-fidelity multi-sensor fusion. Remote Sens. Environ. 2012, 124, 454-465. [CrossRef]

67. Hobbie, J.E.; Carpenter, S.R.; Grimm, N.B.; Gosz, J.R.; Seastedt, T.R. The US long term ecological research program. Bioscience 2003, 53, 21-32. [CrossRef]

68. Symstad, A.J.; Chapin, F.S.; Wall, D.H.; Gross, K.L.; Huenneke, L.F.; Mittelbach, G.G.; Peters, D.P.C.; Tilman, D. Long-term and large-scale perspectives on the relationship between biodiversity and ecosystem functioning. Bioscience 2003, 53, 89-98. [CrossRef]

(C) 2017 by the authors. Licensee MDPI, Basel, Switzerland. This article is an open access article distributed under the terms and conditions of the Creative Commons Attribution (CC BY) license (http:// creativecommons.org/licenses/by/4.0/). 